[Thornton, K. (2006). Notions of Leadership in the New Zealand ECE Centres of Innovation Programme. New Zealand Annual Review of Education, 15, 153-167]

\section{Notions of Leadership in the New Zealand ECE Centres of Innovation Programme}

\section{KATE THORNTON}

\section{Abstract:}

Historically there has been limited recognition of, and research into, notions of leadership in the New Zealand early childhood education (ECE) sector. A study completed in 2005 exploring how leadership is defined and enacted in the New Zealand ECE Centres of Innovation (COI) gives us some insights into leadership in this sector. Although the three COI in this study represent different early childhood services, there were significant similarities in how leadership was enacted. This research found that leadership as defined and enacted in the COI was a shared endeavour and was characterised by courage, commitment and collaboration.

$\mathrm{T}$

he ten year strategic plan for ECE, Pathways to the Future: Ngã Huarahi Arataki sets out how the Government's vision of "lifting the educational achievement of all New Zealand children" will be met (Ministry of Education, 2002a, p. 2). The plan contains three key goals: increasing participation, improving quality and promoting collaborative relationships. Within the goal of improving quality, two key initiatives were signalled: the establishment of six Centres of Innovation (COI) for a three-year term; and the provision of leadership development programmes to strengthen leadership in ECE services. The establishment of COI was intended to showcase "excellence and innovation in ECE" (p. 15). Licensed and chartered early childhood centres that met certain criteria laid down by the Ministry of Education were invited to apply to become COI in late 2002. In order to be among the short-listed centres they needed to be using innovative approaches, providing a quality programme and able to engage in research (Meade, 2003a). The names of the first COI were announced in May 2003. The six inaugural COI selected represented a variety of different services, including state kindergartens, a Kohanga Reo, a Pasifika immersion early childhood centre, a playcentre and an education and care (childcare) centre.

The stated objective of the COI programme was "to help improve quality in early childhood education services by demonstrating competent practice and innovation in early childhood education, and by reflecting - in public - on quality practices in action research" (2003a, p. 1). The centres' role over the three-year period was described in the following extract from the COI package letter:

Each of the centres will be funded and supported by the Ministry to:

- Develop and document innovative learning and teaching practices

- Work with researchers to find out what children gain from these innovative learning and teaching processes

- Share information with others about their innovative learning and teaching practices. (Ministry of Education, 2002b)

According to Anne Meade, the programme coordinator for the first round of $\mathrm{COI}$, the centre responsibilities also signalled a leadership role. She suggested "COIs provide case studies of educative leadership through the curriculum they offer, through their articulation of innovation and willingness to research it, and by demonstrating an ethic of care for colleagues in the sector at large" $(2003 \mathrm{~b}, \mathrm{p}$. 3). These comments were the inspiration for a study into notions of leadership in the COI programme. As a professional development facilitator working in the sector I wished to gain insights into what leadership in quality centres actually involved and how leadership development could be supported.

Leadership within the ECE sector had been virtually ignored in Government policy up until the release of Pathways to the Future (Ministry of Education, 2002a). There was no mention of professional leadership in any of the Government's previous official documents (Scrivens, 2002), and no policy for supporting leadership development. The provision of leadership development programmes is signalled in the strategic plan, though at the time of this study there was no detail on what these programmes may look like. Some leadership training and education opportunities do already exist. However, leadership training and development has had to compete for scarce financial resources 
alongside other professional development areas and has not been seen as a priority.

\section{Existing Understandings of Leadership in the ECE Sector}

A review of current literature from New Zealand and overseas, undertaken as part of this study, depicted a sector in which there was a lack of clarity as to what leadership actually means or looks like. Scrivens (2002, p. 52) summed this up in her comment that "there is still confusion in the minds of leaders, particularly at centre level, about how they should construct leadership." There appears to be no clearly accepted definition of leadership (Ebbeck \& Waniganayake, 2003; Hard, 2004). However, the importance of developing a clear definition has been highlighted by several authors (Bowman \& Kagan, 1997; Hard, 2004; Scrivens, 2002).

Existing models of leadership in the ECE sector explain leadership either as a set of skills or expertise (Bloom, 2003; Kagan \& Bowman, 1997; Rodd, 2001) or as a range of leadership styles (Geoghegan, Petriwskyj, Bower, \& Geoghegan, 2003). Many of these models suggest individual notions of leadership, but models of shared leadership are increasingly being promoted (Hard, 2004; Morgan, 1997; Waniganayake, Morda \& Kapsalakis, 2000). This shift reflects what is happening in the wider education sector, where models of distributed leadership such as teacher leadership, conceptualised by Harris as "a set of behaviours and practices that are undertaken collectively", are being promoted (2003, p. 45)

\section{The Research Study}

This qualitative research study into notions of leadership in the COI employed a case study approach. Three of the six first round COI, New Beginnings Preschool, Wilton Playcentre and Wycliffe Nga Tamariki Kindergarten, agreed to take part in the research. Multiple sources of data were used to help answer the research question: How is leadership defined and enacted in the Centres of Innovation? The data sources included documents such as the centres' research proposals; an interview with Anne Meade, as the national programme coordinator; and focus group discussions with members of the three COI. In the focus discussions, participants were asked how leadership was defined and enacted within their own Centres of Innovation. The following questions were discussed:
- what leadership roles existed.

- how were these were shared; and

- what, if any, new leadership opportunities had arisen from participation in the COI programme?

\section{Research Findings}

What leadership looks like across the COI

Leadership structures varied across the COI. As Meade (2003a) has mentioned, some of the centres had a designated head teacher and others had a structure of distributed leadership. In reality leadership appears to be more shared than hierarchical across the centres in the study. The most overt leadership of the three COI in the study appeared to come from the head teacher at New Beginnings who, because of her larger team and the parent cooperative nature of the management committee, had a large and complex role. There was however, a strong commitment to team work at this centre and all teachers were encouraged to take on leadership roles. ${ }^{1}$ Leadership in the playcentre was shared between parents, with different people taking responsibility for different aspects of leadership, such as curriculum leadership and management leadership. Leadership roles in the kindergarten were also shared between team members, although one person held the designated position of head teacher. These findings reflect the views of both Rodd (2001) and Scrivens (2003), who suggest that leadership varies between contexts and that there is more than one way to demonstrate leadership.

\section{Notions of leadership}

There was considerable variation within and across the centres as to their understandings of the concept of leadership. The head teacher at New Beginnings, who as mentioned above probably had the most complex leadership role, was clear that leadership was about direction and vision. ${ }^{2}$ She was also comfortable with the word leadership. This contrasted with the teachers in her centre who were not sure how they felt about leadership and hadn't really thought about it much. The teachers at Wycliffe Nga Tamariki were uncomfortable about being personally identified as leaders. However, there was some acceptance that the kindergarten was providingleadership through "making others aware of the possibilities." 3 These views fit with Geoghegan et al.'s (2003) study that identified a lack of awareness and some discomfort 
with the concept of leadership among early childhood teachers. This lack of awareness may be attributed in part to the fact that the models they are familiar with promote individual rather than distributed leadership.

Of the three COI studied, the members of the playcentre were best able to articulate what leadership "looked like" in their setting. They were generally comfortable with the concept of emergent leadership, the principle of encouraging turnover in leadership positions, and they were also able to compare leadership in playcentre to other leadership experiences. This difference between playcentre and the other services could be attributed to the emphasis on leadership in playcentre training programmes, and playcentre parents were readily able to compare their previous workplace experiences with the playcentre context. The concept of distributed leadership, which is conducive to a parent cooperative, fits well with the literature that warns against connecting leadership with a role (Hard, 2004; Morgan, 1997; Waniganayake et al., 2000).

\section{Vision, values and beliefs}

The importance of vision to effective leadership is emphasised in much of the literature (Day, Harris, Hadfield, Tolley \& Beresford, 2000; Kagan \& Hallmark, 2001; Lambert, 2003). Having a clear vision to work towards gives direction to an organisation and encourages a culture of continuous improvement. Shared visions, values and beliefs were articulated by the three centres participating in the study in their primary documents and the focus group discussions also revealed a clear commitment to a shared vision.

\section{Centre culture and leadership}

The importance of a collaborative and supportive centre culture was mentioned by the two COI in the study with larger teams. It seemed that teamwork was taken for granted in the kindergarten with the comment that in kindergartens, leadership is a "team thing." ${ }^{3}$ The cultures of different centres are influenced by service-specific features such as philosophy and management structure as well as by centre-specific features such as the personnel working in the centre and the community they serve. Despite these contextual differences, there were strong similarities between the centre cultures in the COI. They all seemed to correspond with Nias, Southworth and Yeoman's (1989) description of collaborative cultures that are characterised by behaviours, attitudes and qualities of help, support, trust and openness (as cited in Fullan \& Hargreaves, 1996). Collaborative cultures tolerate and to some extent encourage disagreement. They also respect and celebrate individual teachers and thereby empower them. The importance of leadership in promoting strong organisational cultures was reinforced by Meade. She linked this with innovative practices saying " to have actually introduced an innovation and to get it accepted and embedded demonstrates that that's in the culture of the place and somebody's got that leadership ability to make it happen." ${ }^{11}$

\section{COI leadership opportunities}

Meade (2003, p. 10) described the dissemination role of the COI as using "their knowledge and skills to be educational leaders horizontally." The "horizontal" leadership opportunities arising from participation in the COI programme were very similar for all COI and involved giving presentations and writing papers and articles. These opportunities were shared among the teams with all the study centres endeavouring to give everyone an opportunity to be involved in dissemination. The expectation that busy teachers will "write, develop online networks and talk to stimulate others in ECE centers to debate and try out new ideas in their practice" (Meade, Ryder \& Henriod, 2004, p. 2) is a challenging one and requires courage on the part of the centres. Advocacy outside the centre is an aspect of leadership that Rodd (1998) believes is neglected by many in leadership positions in the ECE sector. The COI programme has certainly encouraged advocacy through the expectation that centres share information about their innovations with others.

\section{Openness to change}

Openness to change was a characteristic of the three study COI. Meade described how in general the COI "push themselves out of their comfort zones ... and it's usually in response to something either for educational benefit or to benefit the families in some way." ${ }^{1}$ Meade has also observed that the changes made by the COI have been carefully thought through, "if something is presented to them as a pretty important step to consider taking they'll give it a go but they won't just plunge in, they'll do it in a very considered way."

The openness to change noted in the COI can be linked to the collaborative nature of leadership in these centres. Wilson-Evered, Dall and Neale (2001, p. 63) found that "supportive leaders who develop a participative decision-making style will increase support for new ideas 
among individual members of work groups by increasing their morale and increasing support for team objectives." Senge et al. (1999) agree with the importance of a collaborative leadership style suggesting that there is little evidence that "hero-leaders" have any significant success in implementing change, because this top-down drive disempowers others in the organisation. They add "shared commitment to change develops only with collective capability to build shared aspirations" (p. 9).

\section{Collaborative relationships}

Collaborative relationships are clearly a feature of the COI programme. Such relationships go beyond those involving the teaching team to those with research associates, parents and the wider community. The relationship between the educators/teachers and the centre research associates is a particular feature of the COI programme and has been discussed extensively by Meade (2003a; 2003c), Meade et al. (2004), and Podmore (2004). This collaborative way of working links to the way leadership is enacted in these centres. Those people in designated leadership roles were willing to work collaboratively with others in the best interests of the centre as a whole.

\section{Key Notions of Leadership in the COI: Courage, Commitment and Collaboration}

Although leadership is enacted in different ways across the COI programme, consistent with the contexts in which the individual COI operate, three key notions of leadership emerge from this study into leadership in the COI. These are courage, commitment and collaboration. Courage is an aspect of leadership that applies to both leadership within and leadership beyond the COI. In order to introduce and embed an innovation, individuals and centres have had to challenge themselves and their beliefs. Bravery is also required to open your centre up to the scrutiny of others. According to Meade (2003b, p. 6), "sharing ideas with others when still researching and developing them requires courage." Teachers at Wycliffe Nga Tamariki Kindergarten described leadership as being about taking risks and rising to the challenge. Meade agrees when she describes COI as doing "some things that really have pushed them out of their own comfort zones and yet they've done it."1

Public speaking took courage and was described as nerve-wracking by several educators. Courage as a significant aspect of leadership is also mentioned in some of the literature. Grey (2004), in a study of the role of the leader in centre self-review, found that courage and honesty needed to be shown by those in leadership positions for self-review to be effective. The importance of leaders being willing to take risks has been emphasised by Bloom (2003) and Kagan and Bowman (1997); and Kagan and Hallmark (2001) and Scrivens (2000) have emphasised the need for leaders to be courageous.

All the COI have visions, values and beliefs, discussed above, to which they are committed. This commitment, which takes various forms, involves doing what is best for the children attending the centres and for their families. A recently graduated teacher working at New Beginnings Preschool described the "commitment and dedication to doing quality practices" ${ }^{2}$ at her centre. This commitment is not just related to being a COI but is ongoing. Teachers at New Beginnings commented "this isn't put on for the Centre of Innovation ... we were like this before we were chosen." 2 The dedication shown by the COI has been noted by Meade: "I started off feeling really pleased about them but I have just become increasingly respectful and have got a lot of admiration for what they're doing over the time." ${ }^{1}$ The commitment toward realising their shared vision, demonstrated by each of the COI, is a strong indicator of their leadership capacity.

Leadership in the COI studied for this research was characterised by collaboration between team members. This distributed style of leadership was part of the culture of each centre and resulted from the willingness of the designated leader to encourage and support the leadership experiences of others. Waniganayake et al. (2000, p. 18) suggest that this style of leadership "offers increased vitality and strength to the whole organisation." Not all leadership tasks were shared within the centres, and individuals took defined leadership roles at certain times. However, major decisions were made by the whole group and everyone was encouraged to participate in leadership opportunities, such as research dissemination. Meade has noted that "it was a very genuine and valid comment in their initial papers that they were putting in to the Ministry that they work collegially, that they worked as a team and that's been demonstrated since in every case."1

Collaborative leadership in the COI fits with the findings from the unpublished Best Evidence Synthesis into the effects of leadership on early childhood services. In it, (Scrivens, 2004, p. 10) cites Johanssen (1997) who suggests that learning and teaching is improved by "the development of a pedagogically focused teaching culture that 
encourages co-operation, collaboration and pleasure in professional work." This fits with the collaborative cultures described above and also with the passion and enthusiasm of the teacher leaders in the COI. Scrivens also found evidence that "horizontal management styles encourage staff to work more closely together and work more collaboratively with parents" (Lara, McCabe \& Brooks-Gunn, as cited in Scrivens, p. 10). This relates to the concept of distributed leadership which was evident in the study centres.

\section{Analysis of Notions of Leadership in the COI in the Literature}

Although individuals involved in leadership within the COI show many of the characteristics of effective leadership promoted in the literature, it is the shared nature of leadership in the COI that warrants further discussion. The contribution that the notion of distributed leadership makes to the strength of an organisation is acknowledged by several authors writing about the ECE sector (Ebbeck \& Waniganayake, 2003; Geoghegan et al., 2003; Waniganayake et al., 2000). Of the models from outside the ECE sector, the concept of teacher leadership (Harris, 2003; Lambert, 2003) fits well with notions of leadership as enacted in the COI. Lambert's description of teacher leaders as "those whose dreams of making a difference have either been kept alive or have been reawakened by engaging with colleagues and working within a professional culture" (p. 33), fits with the passion and enthusiasm shown by those working in the COI. Harris suggests that teacher leadership "engages all those within the organisation in a reciprocal learning process that leads to collective action and meaningful change"(p. 46).

There is still an important role for the designated or formal leader in the distributed model of leadership. According to Harris $(2002$, p. 2), "the job of those in formal leadership positions is primarily to hold the pieces of the organisation together in a productive relationship." This view is supported by the comment made in the playcentre group discussion that the president's role was not to make decisions but to ensure that decisions got made. ${ }^{4}$ Positional leaders also have an important influence on the organisational culture of the service. Leaders who promote and model respectful and collaborative relationships, and provide support and mentoring, encourage their colleagues to become involved in the leadership of the centre. The amount of direction given by those in formal leadership positions may depend on the composition and maturity of the group (Scrivens, 2003)

\section{Defining leadership in the COI}

Several authors have suggested that a definition is necessary to the development of an understanding of leadership (Bowman \& Kagan, 1997; Hard, 2004; Lambert, 2003; Scrivens, 2002). As a result of this study, leadership in the COI can be defined as working collaboratively in a learning community towards a shared vision. This requires courage and commitment. The diagram below presents a model of notions of leadership in the COI.

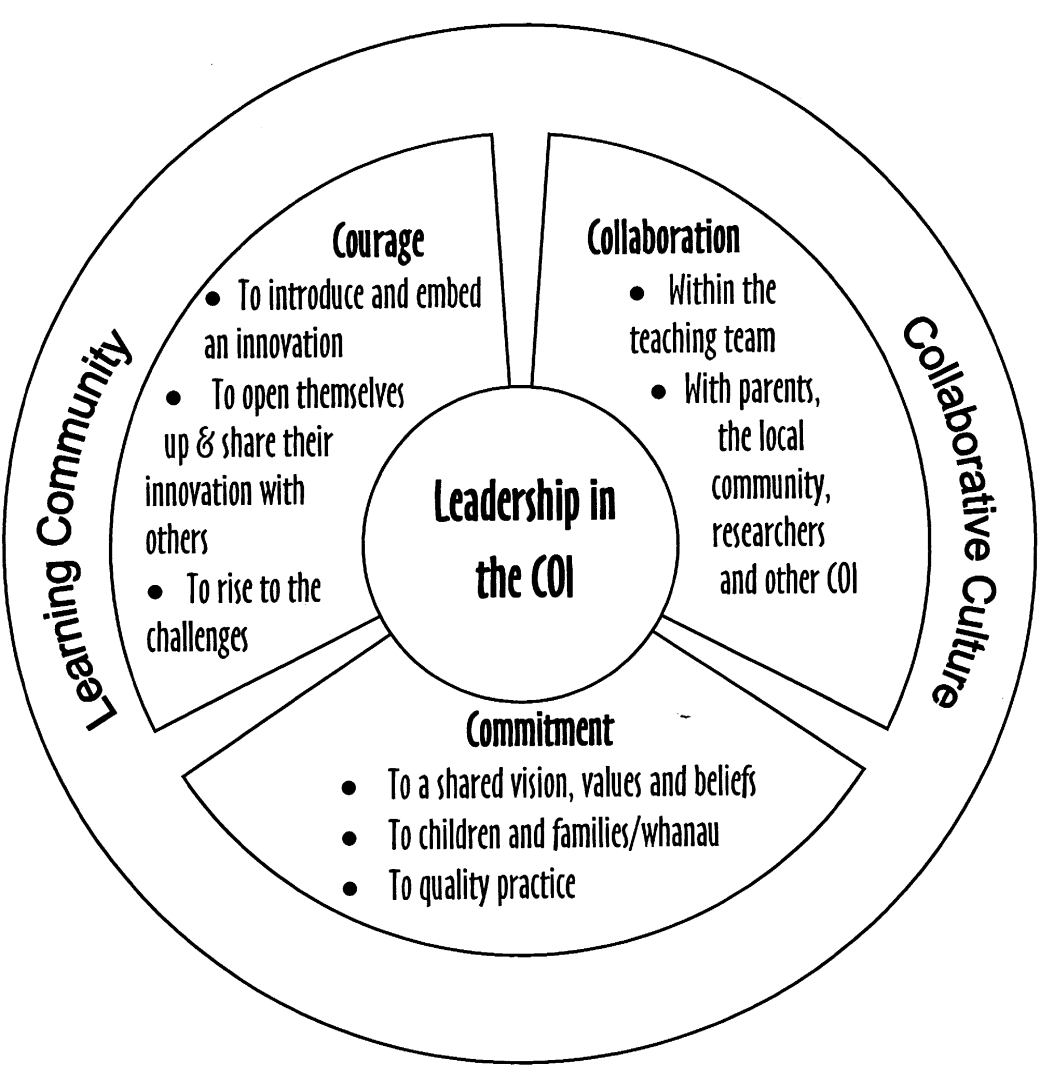

Figure 1 Model of notions of leadership in the COI 
The leadership characteristics of courage, commitment and collaboration are enacted in the COI within the framework of a learning community and a collaborative culture. The centres were all committed to providing a quality service for the children attending the centre and their families. They had discussed and articulated clear visions, values and beliefs and had shown courage in the way in which they rose to the challenges of introducing and embedding an innovation and sharing this with others. The COI all worked collaboratively with the groups in their learning communities, including parents, researchers and colleagues.

\section{Implications for Leadership in the ECE Sector}

The findings from this study exploring notions of leadership in the COI cannot be generalized beyond the COI programme. However we can learn from the notions of leadership defined and enacted by these centres which have been recognised as being of high quality. The study findings, that leadership is concerned with working collaboratively in a learning community towards a shared vision, could lead to an improved understanding of "the contributing values, behaviours and assumptions" of the cultures of excellent centres suggested by Hatherly (1997, p. 63) and what leadership might be like "within a professional community of learners framework" (Scrivens, 2004, p. 19).

This study has highlighted a lack of clarity about educators' understandings of leadership, and a lack of support for leadership development. Although leadership is definitely being shown within and by these quality centres, this needs to be acknowledged and articulated. As Lambert (2003, p. 4) has indicated, "how we define leadership frames how people will participate in it." The definition developed in this study could provide a starting point for others to consider. Any broader definition needs to be inclusive of the way leadership is enacted in different services and also needs to promote the concept of collaborative leadership.

\section{Conclusion}

This study revealed notions of leadership that were characterised by courage, commitment and collaboration. The innovative approaches of the COI appear to be due in no small part to the collaborative centre cultures in which innovation is encouraged, educators feel valued and supported, and there is regular reflection and a commitment to continuous improvement. Those in leadership positions in the COI have promoted these collaborative cultures and through their example teacher leadership has been encouraged. The model of teacher leadership, which is a feature of the COI, needs to be encouraged in the whole ECE sector to ensure that teachers working with young children work collegially, are committed to quality practices and maintain their dedication and enthusiasm. According to Hargreaves and Fink, "leadership must be embedded in the hearts and minds of the many, and not just rest on the shoulders of an heroic few" (2003, p. 446). Those responsible for teacher education and the development of leadership support programmes need to work towards ensuring this statement becomes a reality.

The COI not only provide case studies of educative leadership (Meade, 2003c) but also case studies of learning communities. Bloom has defined learning communities as places where "collective aspirations are set free, new patterns of thinking are nurtured, and the organisation expands its capacity for constructive and innovative problem solving" (2003, p. 55). These learning communities include not only the educators but also the parents, researchers and members of the wider community. Leadership as defined and enacted in the COI is a shared endeavour and this model of working collaboratively in a learning community towards a shared vision is one that the rest of the sector can learn from.

This research study was carried out in the middle of the three-year term of the inaugural COI programme and provides a snapshot of how leadership was defined and enacted by the centres in the programme at this time. Since the completion of the study, two of the second round COI have made processes of educational leadership a focus of their research. We can therefore look forward to continued research into notions of educational leadership in the COI. It is to be hoped that both this study and future leadership research will contribute to a greater recognition of the importance of leadership and leadership development. This will have benefits for the ECE sector in New Zealand as a whole. To quote a Chinese proverb:

If you want one year of prosperity, grow grain.

If you want ten years of prosperity, grow forests.

If you want one hundred years of prosperity, grow leaders

(in Kagan and Hallmark, 2001, p. 7). 


\section{Notes}

1. Information from an interview with Anne Meade, 2004

2. Quotes from Focus Discussion Group 1, 2004.

3. Quotes from Focus Discussion Group 3, 2004

4. Quotes from Focus Discussion Group 2, 2004

\section{References}

Bloom, P. J. (2003). Leadership in action: How effective directors get things done. Lake Forest: New Horizons.

Bowman, B., \& Kagan, S. (1997). Moving the leadership agenda. In S. Kagan \& B. Bowman (Eds.), Leadership in early care and education (pp. 157-160). Washington, DC: National Association for the Education of Young Children.

Day, C., Harris, A., Hadfield, M., Tolley, H., \& Beresford, J. (2000). Leading schools in times of change. Buckingham: Open University Press.

Ebbeck, M., \& Waniganayake, M. (2003). Early childhood professionals: Leading today and tomorrow. Sydney: MacLennan \& Petty.

Fullan, M., \& Hargreaves, A. (1996). What's worth fighting for in your school? New York: Teachers College Press.

Geoghegan, N., Petriwskyj, A., Bower, L., \& Geoghegan, D. (2003). Eliciting dimensions of educational leadership in early childhood education. Journal of Australian Research in Early Childhood Education, 10(1), 12-21.

Grey, A. (2004). The quality journey: Is there a leader at the helm? New Zealand Research in Early Childhood Education, 7, 91-102.

Hard, L. (2004). How is leadership understood in early childhood education and care? Journal of Australian Research in Early Childhood Education, 11(1), 123-131.

Hargreaves, A., \& Fink, D. (2003). Sustaining leadership. In B. Davies \& J. West-Burnham (Eds.), Handbook of educational leadership and management (pp. 435-450). London: Pearson Education.

Harris, A. (2002). Distributed leadership in schools: Leading or misleading? Retrieved 22 November, 2004 from

$<$ www.icponline.org/feature_articles/f14-0.2htm $>$
Harris, A. (2003). Teacher leadership: A new orthodoxy. In B. Davies \& J. West-Burnham (Eds.), Handbook of educational leadership and management (pp. 44-50). London: Pearson Education.

Hatherly, A. (1997). Phoenix rising? A case study of organisational culture of a childcare centre. Unpublished Report, Massey University, Palmerston North.

Kagan, S., \& Bowman, S. (1997). Leadership in early care and education: Issues and challenges. In S. Kagan \& B. Bowman (Eds.), Leadership in early care and education (pp. 3-8). Washington, DC: National Association for the Education of Young Children.

Kagan, S., \& Hallmark, L. (2001). Cultivatingleadership in early care and education. Childcare Information Exchange, 140, 7-12.

Lambert, L. (2003). Leadership capacity for lasting school improvement. Alexandria, VA: Association for Supervision and Curriculum Development.

Meade, A. (2003a, October). ECE Centres of Innovation in New Zealand. Paper presented at the Leadership and Management in the Early Years Conference, Pen Green Leadership Centre, Corby, Northamptonshire.

Meade, A. (2003b, September). Shaping early childhood today: The role of the leader. Paper presented at the Eighth Early Childhood Convention, Palmerston North.

Meade, A. (2003c). Forging new partnerships. New Zealand Education Review, 8(35), 6.

Meade, A., Ryder, D., \& Henriod, S. (2004, July). Promoting dialogue in early childhood education centres of innovation. Paper presented at the New Zealand Action Research Conference, Christchurch.

Ministry of Education. (2002a). Pathways to the future: Ngā Huarahi Arataki. Wellington: Learning Media.

Ministry of Education. (2002b). Centres of Innovation package letter. Retrieved 15 November, 2003 from <www.minedu.govt.nz>

Morgan, G. (1997). What is leadership? Walking around a definition. Boston: Center for Career Development in Early Care and Education.

Podmore, V. (2004). Collectivism, communities, and constellations: Some reflections on early childhood innovations 2003. New Zealand Annual Review of Education, 13, 189-204. 
Rodd, J. (1998). Leadership in early childhood (2nd ed.). Australia: Allen \& Unwin.

Rodd, J. (2001). Building leadership expertise of future early childhood professionals. Journal of Early Childhood Teacher Education, 22, 9-12.

Scrivens, C. (2000). Leadership: What do we want it to be like? Early Education, 22, 33-37.

Scrivens, C. (2002). Redefining leadership for early childhood services. Delta, 54(1\&2), 43-56.

Scrivens, C. (2003). Educational leadership: What might we learn from research in schools? Early Education, 31, 29-35.

Scrivens, C. (2004, November). Leadership in early childhood services: How can we discover what matters for children? Paper presented at the New Zealand Early Childhood Research Symposium, Wellington.

Senge, P., Kleiner, A., Roberts, C., Ross, R., Roth, G., \& Smith, B. (1999). The dance of change: The challenges of sustaining momentum in a learning organisation. London: Nicholas Brealey Publishing.

Waniganayake, M., Morda, R., \& Kapsalakis, A. (2000). Leadership in childcare centres: Is it just another job? Australian Journal of Early Childhood, 25(1), 13-19.

Wilson-Evered, E., Dall, P., \& Neale, M. (2001). The influence of leadership on innovation at work. In K. Parry (Ed.), Leadership in the antipodes: Findings, implication and a leadership profile (pp. 46-73). Wellington: Victoria University of Wellington, Institute of Policy Studies and the Centre for the Study of Leadership.

\section{The author}

Kate Thornton is a lecturer in the School of Early Childhood Teacher Education at Victoria University of Wellington. She has had teaching experience in the New Zealand secondary, early childhood, and tertiary sectors. In 2005, she completed an MEd thesis exploring notions of leadership in the ECE Centres of Innovation programme. She is currently involved in full-time doctoral study on the topic "The use of ICT to facilitate leadership in the ECE sector." 